\title{
Mass and Charge State Assignment for Proteins and Peptide Mixtures Via Noncovalent Adduction in Electrospray Mass Spectrometry
}

\author{
John B. Cunniff and Paul Vouros \\ Department of Chemistry and Barnett Institute of Chemical Analysis, Northeastern University, \\ Boston, Massachusetts, USA
}

\begin{abstract}
A method has been developed that takes advantage of the formation of noncovalent compounds in electrospray mass spectrometry. Mixtures of proteins and peptides are shown to produce an intense ion that corresponds to a 1:1 complex with a crown ether (18-crown-6). Although the crown ether may be added directly to the solution, for the current experiments it is introduced via the methanol liquid sheath. The spacing of these complexed species in the mass spectrum allows unambiguous determination of the charge state of the ions and their actual mass. Through constant neutral loss scans, charge state may be determined, mass assigned, spectra simplified, and chemical noise may be reduced for the analysis of complex peptide samples without chromatographic separation. Finally, the prevalence of single complexation permits mass assignments based on the mass difference of a single protein ion and its complexed form at any charge state. In essence, the method performs a separation based on charge state. It can be used to complement chromatographic separation and deconvolution algorithms for the electrospray mass spectrometry analysis of peptide-protein mixtures. () Am Soc Mass Spectrom 1995, 6, 1175-1182)
\end{abstract}

$\mathrm{E}$ lectrospray ionization (ESI) mass spectrometry has generated tremendous excitement in the last few years as publications that involve the technique have grown at an exponential rate [1]. Since the beginning of the 1990s, electrospray has been utilized extensively and in many ways has revolutionized the field of mass spectrometry. Its basic strength lies in its ability to detect large polar molecules within a relatively small mass-to-charge ratio range and also in its ability to be coupled with existing separation techniques. One drawback to the technique lies in the potential difficulty in determination of the charge states (and thus the actual masses) of the observed ions. To overcome this former problem, Neubauer and Anderegg [2] proposed the addition of sodium acetate to the mobile phase during a liquid chromatography/ electrospray ionization-mass spectrometry experiment, whereas Senko and co-workers [3] utilized the addition of $\mathrm{Cu}^{2+}$. The main advantage of $\mathrm{Cu}^{2+}$ over $\mathrm{Na}^{+}$lies in its larger mass, which thus provides for a larger mass separation than sodiated ions. Along the same lines, we recently introduced the concept of mass and charge assignment via crown ether adduction for single small peptide standards [4]. Crown ethers are more amenable than cations toward the task of mass and charge assignment in electrospray mass spectrometry because of (1) their relatively large molecular

Address reprint requests to Dr. Paul Vouros, 101 Hurtig Hall, Northeastern University, Boston, MA 02115. weight, (2) their neutral charge state, (3) the large abundance of the peptide-crown ether ion complexes, and (4) the ability to exploit constant neutral loss (CNL) scanning on the crown ether complexes. Within this work [4], it was demonstrated that a single crown ether-peptide complex ion predominates over multicomplexed ions within the spectrum regardless of the charge state (trace levels of double complexation may be evident). It also was demonstrated that the mass of single peptides could be determined accurately from the use of constant neutral loss (CNL) scanning and the following algorithm:

$$
\begin{aligned}
{[(A-B / n) \times n]-n } \\
\quad=\text { molecular weight of the peptide }
\end{aligned}
$$

where $A$ is the precursor mass-to-charge ratio determined from the constant neutral loss spectra, $B$ is the mass of the crown ether employed, $n$ is any integer $(1,2,3$, etc.) and consequently the charge state and number of adducted protons, and $B / n$ is the selected constant neutral loss.

Within the last four years, the investigation of ion formation as well as studies of a variety of noncovalent interactions and conformations of biopolymers by ESI has begun and is currently being pursued vigorously $[4-21]$. This has been a somewhat controversial area because the precise origin of these species and the mechanism of ion desorption are still unclear. An excellent recent review of existing theories of ion desorp- 
tion within ESI is given by Kebarle and Tang [22]. It must be pointed out here that it is not our current intention to determine the origin of noncovalent species in ESI, but rather to exploit them. With the introduction of a noncharged noncovalent adduct, such as a crown ether, which remains bound to the analyte within the gas phase, we now can utilize more fully the tandem mass spectrometry capabilities with which so many commercial electrospray mass spectrometers are currently equipped. With crown ether adduction, the technique of constant neutral loss scanning now can be applied to biologically important compounds not normally prone to losing neutral fragments.

The study of crown ether complexes in both the solution and gas phase is not new in mass spectrometry ([23-32] and Cunniff, J. B.; Vouros, P., to appear). Several books detail the findings of studies that involve crown ether complexes [33-37]. The selection of the 18-crown-6 ether (Structure 1) as a noncovalent complexing agent was made because it forms an abundant ion complex with peptides, because it is soluble in our methanol sheath liquid, and because it is a neutral species that will not adversely affect the electrospray system. It is also readily available from commercial sources.

In this article we report on the further utilization of the concept of adduct formation via complexation with a crown ether toward the determination of charge states of electrospray ions and demonstrate its general applicability to the analysis of complex mixtures of peptides, proteins, or combinations thereof.

\section{Experimental}

\section{Mass Spectrometer and Interface}

A Finnigan-MAT TSQ700 (Finnigan-MAT, San Jose, CA) triple quadrupole mass spectrometer equipped

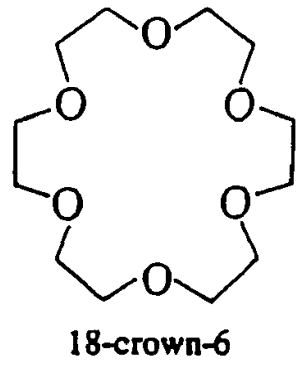

Structure 1. Structure of 18-crown-6 crown ether.

with an electrospray ionization source was used. The stainless steel needle supplied with the instrument was replaced with a polyimide-coated fused silica capillary through which solutions were continuously infused. The interface consisted of a coaxial methanol liquid sheath used for introduction of $0.02-\mathrm{M} 18$ crown-6, as well as a coaxial gas sheath. The electrospray needle was maintained at $+4500 \mathrm{~V}$ and operated in the positive ion mode. 100 scans were averaged for each spectrum. The scanning rate varied from 850 to $1000 \mathrm{u} / \mathrm{s}$. For constant neutral loss scans, the collision voltage was set at $-20 \mathrm{~V}$, and a pressure of 1.5 -mtorr argon was maintained within the collision cell.

\section{Chemicals and Solutions}

The 18-crown 6 (MW 264) was obtained from Sigma Chemical Co. (St. Louis, MO). Peptides and proteins ( $>98 \%$ purity) also were purchased through Sigma Chemical.

Four solution mixtures were prepared in distilleddeionized water and are described in Table 1. Standard

Table 1.

\begin{tabular}{|c|c|c|c|c|}
\hline Solution & Compounds & Amino acid sequence & $M W(u)$ & Concentration \\
\hline \multirow[t]{3}{*}{1} & Bradykinin & (Arg-Pro-Pro-Gly-Phe-Ser-Pro-Phe-Arg) & 1.060 & $100 \mu \mathrm{g} / \mathrm{mL}$ \\
\hline & MRFA & (Met-Arg-Phe-Ala) & 524.3 & $100 \mu \mathrm{g} / \mathrm{mL}$ \\
\hline & Myoglobin & - & 16.952 & $1 \mathrm{mg} / \mathrm{mL}$ \\
\hline \multirow[t]{11}{*}{2} & A & Val-Gly-Ser-Glu & 390.4 & $100 \mu \mathrm{g} / \mathrm{mL}$ \\
\hline & B & Val-Gly-Asp-Glu & 418.4 & $100 \mu \mathrm{g} / \mathrm{mL}$ \\
\hline & $\mathrm{C}$ & Glu-His-Pro-Gly & 420.4 & $100 \mu \mathrm{g} / \mathrm{mL}$ \\
\hline & D & Arg-Gly-Asp-Ser & 433.4 & $100 \mu \mathrm{g} / \mathrm{mL}$ \\
\hline & $\mathbf{E}$ & Arg-Gly-Glu Ser & 447.4 & $100 \mu \mathrm{g} / \mathrm{mL}$ \\
\hline & $\mathbf{F}$ & Thr-Lys-Pro-Arg & 500.6 & $100 \mu \mathrm{g} / \mathrm{mL}$ \\
\hline & $\mathbf{G}$ & Phe-Leu-Glu-Glu-Val & 635.7 & $100 \mu \mathrm{g} / \mathrm{mL}$ \\
\hline & H & Phe-Leu-Glu-Glu-Ile & 649.7 & $100 \mu \mathrm{g} / \mathrm{mL}$ \\
\hline & 1 & Lys-Pro-Pro-Gly-Phe-Ser-Pro-Phe-Arg & $1,032.2$ & $100 \mu \mathrm{g} / \mathrm{mL}$ \\
\hline & $J$ & His-Asp-Met-Asn-Lys-Val-Leu-Asp-Leu & $1,084.3$ & $100 \mu \mathrm{g} / \mathrm{mL}$ \\
\hline & K & Asp-Arg-Val-Tyr-lle-His-Pro-Phe-His-Leu & 1.296 .5 & $100 \mu \mathrm{g} / \mathrm{mL}$ \\
\hline 3 & Myoglobin & - & 16.952 & $1 \mathrm{mg} / \mathrm{mL}$ \\
\hline 4 & Cytochrome $c$ & - & 12,360 & $1 \mathrm{mg} / \mathrm{mL}$ \\
\hline
\end{tabular}


three letter abbreviations are used to designate the amino acids.

\section{Results and Discussion}

\section{Extraction of a Peptide from a Peptide-Protein Mixture}

The spectrum of solution 1 is presented in Figure 1a. No 18-crown-6 was present in the $\mathrm{MeOH}$ sheath during the acquisition of this spectrum. The doubly charged ion of bradykinin shows up at $m / z 531$ $[(1060+2) / 2]$. The singly charged ion of bradykinin is buried under the signal of the myoglobin ion at $m / z$ 1060.5. It should be pointed out that without the observation of either cation adducts $[2,3]$ or a chromatographic separation, the mass and charge state of the peptide could not be assessed. For example, the ion at $m / z 531$ may correspond to a peptide with MW 530 or the ion at $m / z 525$ may correspond to a doubly charged peptide of MW 1049.5. It is also possible that these ions may be sodium adducts or multimers. A normal scan spectrum of the same solution, but with the addition of 18-crown-6 to the methanolic sheath is shown in Figure 1b. Although it may be possible to discern the charge states of the peptides from this spectrum, it is too complex for practical utilization. A CNL scan that monitors the loss of $132 \mathrm{u}$ [which corresponds to loss of 18-crown-6 from a doubly charged species (264/2)] of this solution yields the spectrum of Figure 1c. Because only a doubly charged species will lose a neutral fragment that corresponds in "mass" to $132 \mathrm{u}$, no ions related to the protein are present. In essence, the 132-u CNL scan for solutions infused with 18-crown-6 yields a spectrum indicative of only doubly charged species. This effectively constitutes a mass spectrometric extraction of doubly charged peptide ions from a multitude of protein ions (charge states $>2$ ).

It should be pointed out that the masses that we have superimposed on the figures are, in fact, the mass-to-charge ratio of the ions that are actually detected by the mass spectrometer. The masses reported by the mass spectrometer during a CNL scan are actually calculated parent masses. It should be possible to rewrite the software so as to display the actual ions that impinge on the detector and thus eliminate the need for an external calculation.

\section{Mass Assignments and Simplification of a Spectrum of a Complex Peptide Mixture}

The mass spectrum of solution 2, which contains 11 peptides, is shown in Figure 2. No 18-crown-6 was present in the $\mathrm{MeOH}$ sheath during the acquisition of this spectrum. The spectrum is complex and interladen with sodium adducts. The peptide A (Table 1) ion in Figure 2 is detected only as a sodiated species and is not detected as a protonated species. There is also some overlap of singly charged species with doubly a

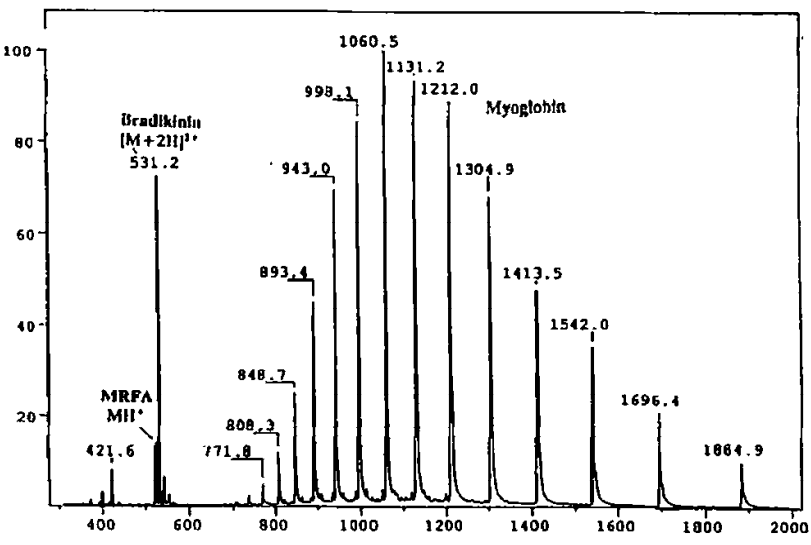

b

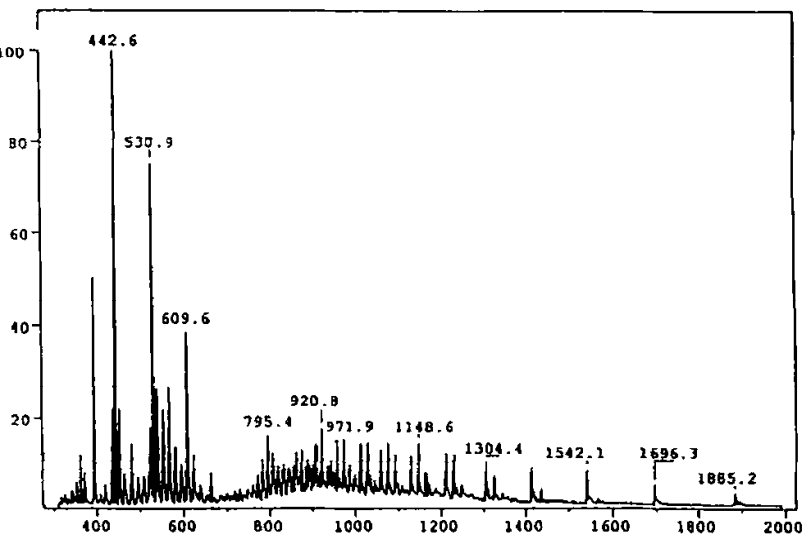

C

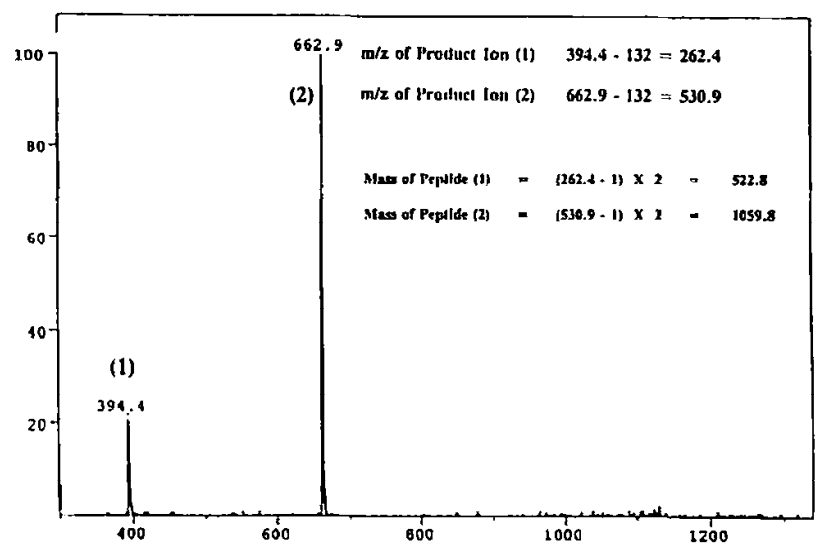

Figure 1. (a) Mass spectrum of the solution that contains MRFA, bradykinin, and apomyoglobin in water with an $\mathrm{MeOH}$ sheath. (b) The same solution with an $18-\mathrm{crown}-6 / \mathrm{MeOH}$ sheath. (c) CNL (132 u) of the same solution.

and triply charged ion peaks. This overlap introduces a serious complication, because the singly charged ions are effectively "hidden" by the multicharged peaks and are likely to go undetected by conventional deconvolution algorithms. Furthermore, cation addition to help identify charge states is of no help when there is such peak overlap. For our current example, this possibility is reflected in the overlap of the doubly protonated peptide $\mathrm{K}$ with the singly protonated peptide $\mathrm{H}$. 


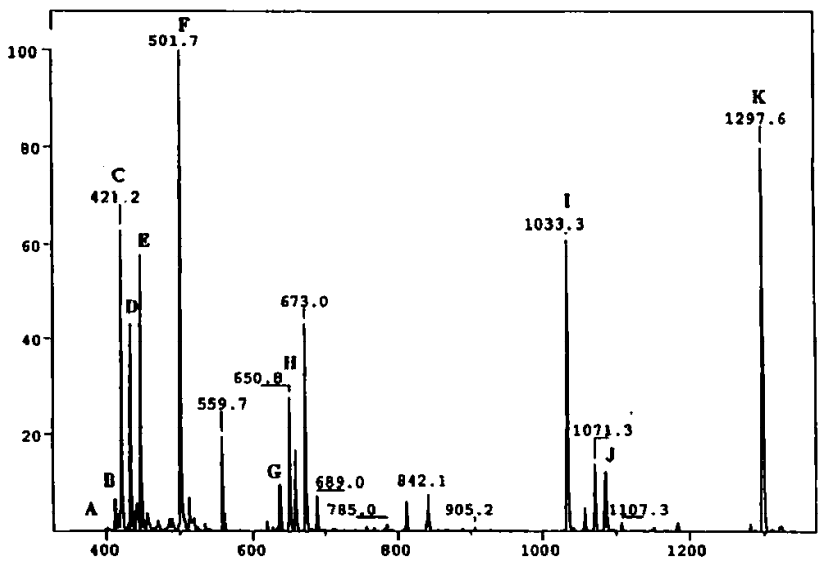

Figure 2. Mass spectrum of 11 peptides (see solution 2 in Experimental for peak assignments) in water with an $\mathrm{MeOH}$ sheath (no crown ether in the sheath).

The ion of the doubly sodiated-doubly charged peptide $\mathrm{K}$ also overlaps with that of the singly sodiated-singly charged peptide $\mathrm{H}$. Peptide $\mathrm{H}$ therefore may go undetected. There is also an overlap of the ions of the singly protonated peptide $\mathrm{D}$ and the triply protonated peptide $\mathrm{K}$.

Singly Charged Ions (CNL 264 u). The 264-u CNL scan [which corresponds to 18-crown-6 loss from a singly charged species (264/1)] of solution 2 (Table 1) yields the spectra of Figure 3 . Note the simplicity of the spectra and the absence of the sodiated peaks (these do not form detectable complexes with the crown ether). Although peptide A could be detected only as a sodium adduct (which could lead to an improper mass assignment) in the normal spectrum (Figure 2), it appears as an intense protonated-complexed ion in the 264-u CNL spectrum (Figure 3a). It also is shown that the ion at $m / z 650.8$ (peptide $\mathrm{H}$ ) in Figure 2 is comprised at least partly of a singly charged species and not solely the doubly charged ion of peptide K (MW 1296.5). In fact, the crown ether-protonated complex is evident for all 11 peptides. The ions at $m / z 781.3(517+264)$ and $807(543+264)$ are indicative of singly charged peptides of mass 517.3 and 543, respectively. These ions are actually the doubly charged ions of peptides I and $J$ and the apparent loss of 264 mass units actually stems from the loss of two crown ethers from the doubly charged ions. As mentioned previously, the occurrence of double complexation complicates the spectral interpretation. For this reason, a CNL 132 also must be performed on peptide mixtures. The fact that the ions at $m / z 517$ and 543 are actually doubly charged species is readily determined as discussed in subsequent text.

Doubly Charged Ions (CNL 132 u). The CNL (132-u) spectrum, which corresponds to the loss of 18-crown-6 from a doubly charged species (264/2) of solution 2 , is shown in Figure 4. As expected, this spectrum is even a

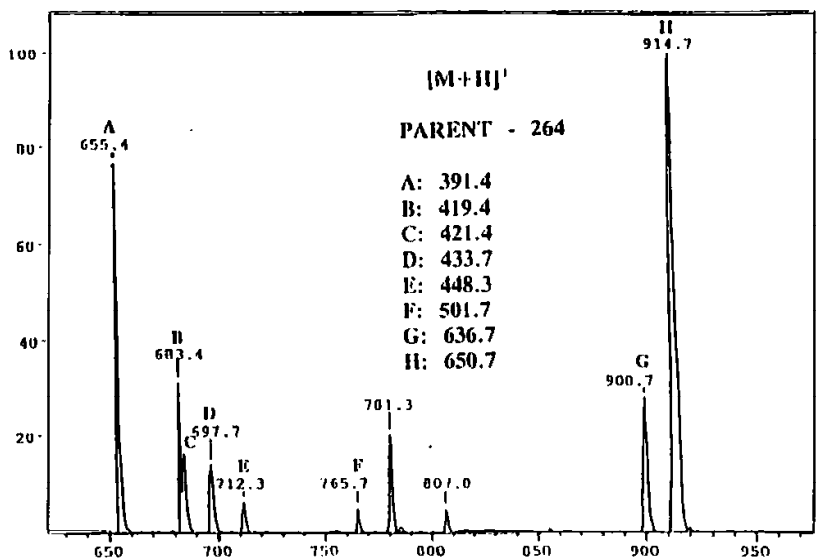

b

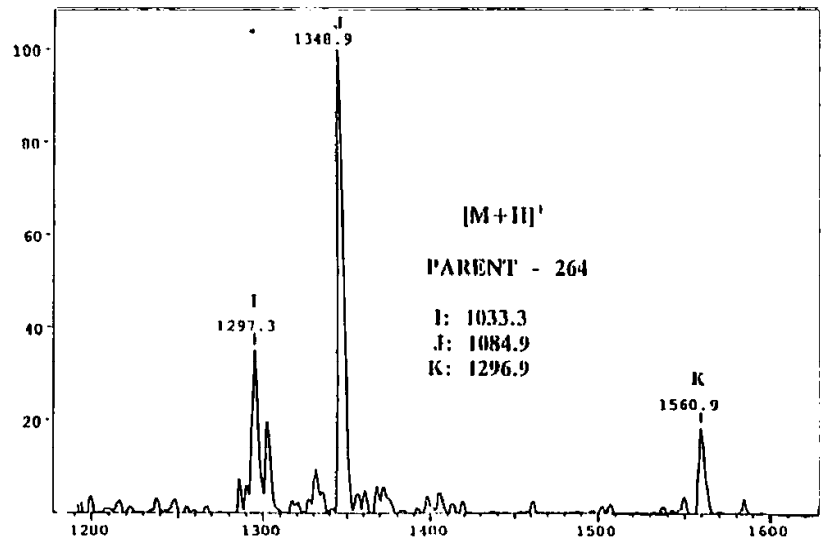

Figure 3. (a), (b) CNL (264-u) spectrum of 11 peptides in water with an 18 -crown-6/MeOH sheath (single charged spectrum).

simpler than its singly charged counterpart because of the presence of fewer doubly charged than singly charged species. All the doubly charged species are evident in the spectrum. The fact that the ion peak at $m / z 650.8$ in Figure 3 also contains a doubly charged ion (doubly charged peptide $\mathrm{K}$ ) is now corroborated.

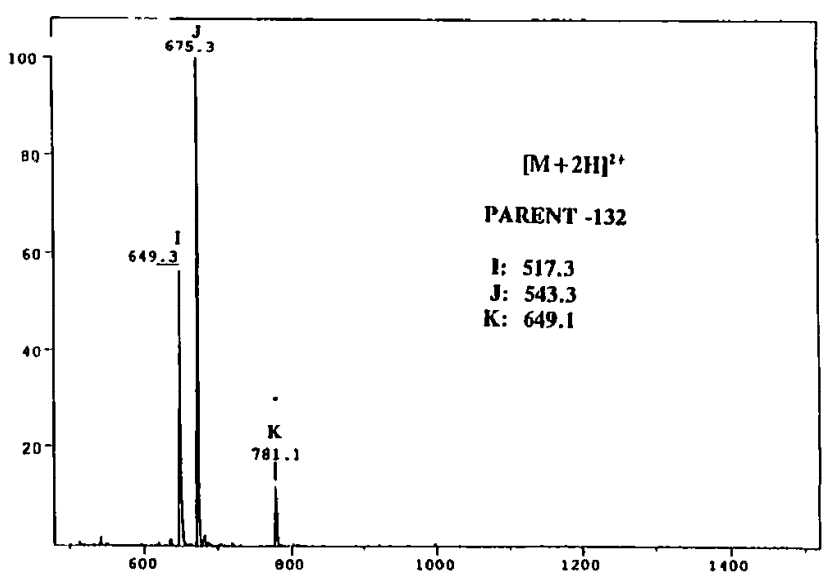

Figure 4. CNL (132-u) spectrum of 11 peptides in water (solution 3) with an $18-c r o w n-6 / \mathrm{MeOH}$ sheath (double charged spectrum). 


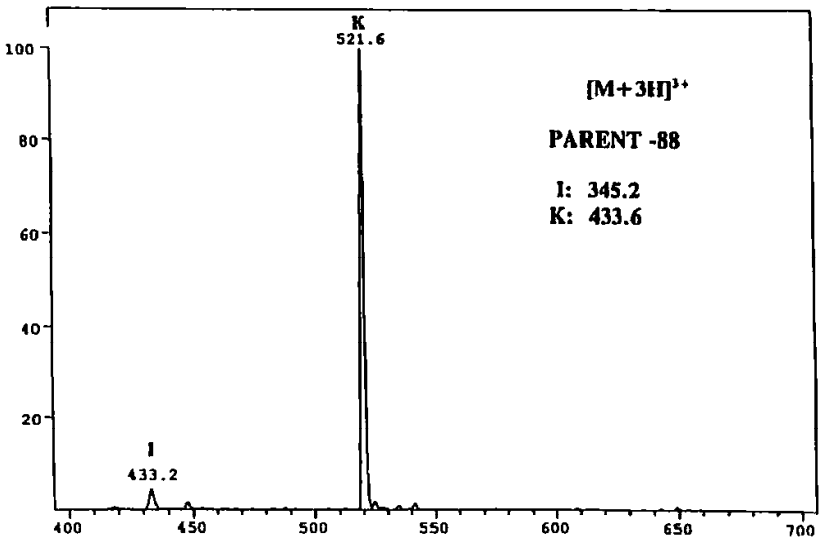

Figure 5. CNL (88-u) spectrum of 11 peptides in water with an 18-crown-6/MeOH sheath (triple charged spectrum).

The potential misinterpretation of charge states that was evident for the two doubly charged-doubly complexed ions observed in the CNL (264) spectrum is not possible due to double complexation within a CNL (132) experiment. The reason for this is that a doubly charged-doubly complexed species will not lose $132 \mathrm{u}$. It should be noted that, theoretically, a misinterpretation is possible if a quadruply charged-doubly complexed ion is introduced into the collision chamber. In general, peptides that form prominent quadruply charged ions also form prominent triply charged species. A scan for triply charged ions (see below) can rule out the possibility of quadruply charged-doubly complexed ion contributions to the CNL (132 scan) by the absence of the corresponding triply charged ion.

Triply Charged Ions (CNL 88 u). The CNL of $88 u$ [which corresponds to loss of 18-crown-6 from a triply charged species (264/3)] for solution 2 yields the spectrum of Figure 5. This spectrum, like the one generated by the doubly charged species, is quite simplified because there are few triply charged species in this solution.

\section{Mass Assignment of Proteins}

To assess the general analytical utility of the noncovalent crown ether complexation process, we next considered the mass spectra generated from the crown ether interaction with proteins. Two examples are presented here.

Figure 6 shows the spectrum of myoglobin (solution 3) analyzed with the 18-crown-6 present in the liquid sheath. The most striking feature in this spectrum is that single complexation predominates even though the protein contains a multitude of charges and despite a large excess of crown ether in the aspirated solution. This is not to say that double or triple complexation does not occur to any degree, but simply that the $1: 1$ complex is clearly the most dominant complex

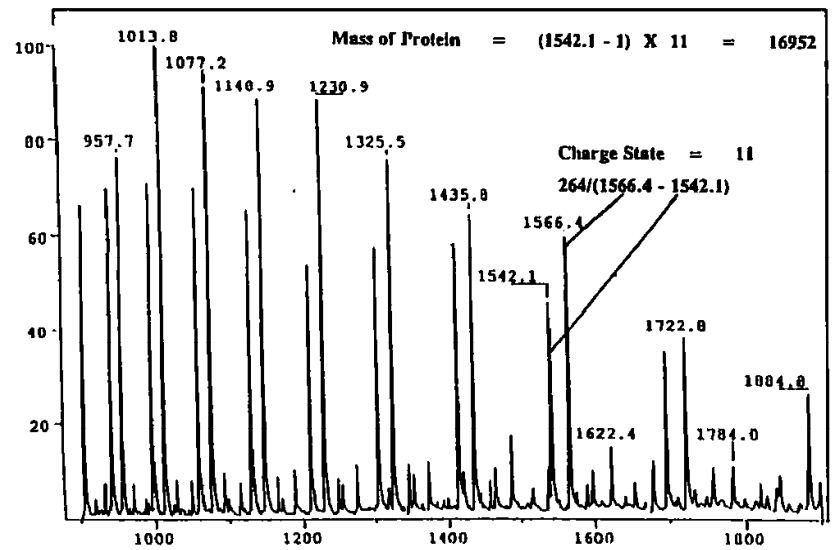

Figure 6. Mass spectrum of apomyoglobin in water with an $18-\mathrm{crown}-6 / \mathrm{MeOH}$ sheath. The asterisk $\left({ }^{*}\right)$ indicates the 18 crown- 6 adduct.

species. Although the predominance of single complexation was evident in the multiply charged peptides, it was unexpected with the highly charged proteins. The fact that single complexation predominates with proteins is fortunate because it greatly simplifies the spectra.

The spectrum of Figure 7 demonstrates that multiple complexation (up to three or four crown ether molecules) with cytochrome $c$ is much more evident than it has been in previous examples, although the singly complexed species are still predominant. Although the reasons for this are not totally clear, it may be due in part to the abnormally large percentage of lysines present in cytochrome $c$ (19 lysines/104 amino acids). It is interesting also to note that the number of crown ethers that are attached to both myoglobin and cytochrome $c$ appears to be independent of the charge state. A priori one might reasonably expect that a larger number of crown ethers would complex to the more highly charged species due to the greater avail-

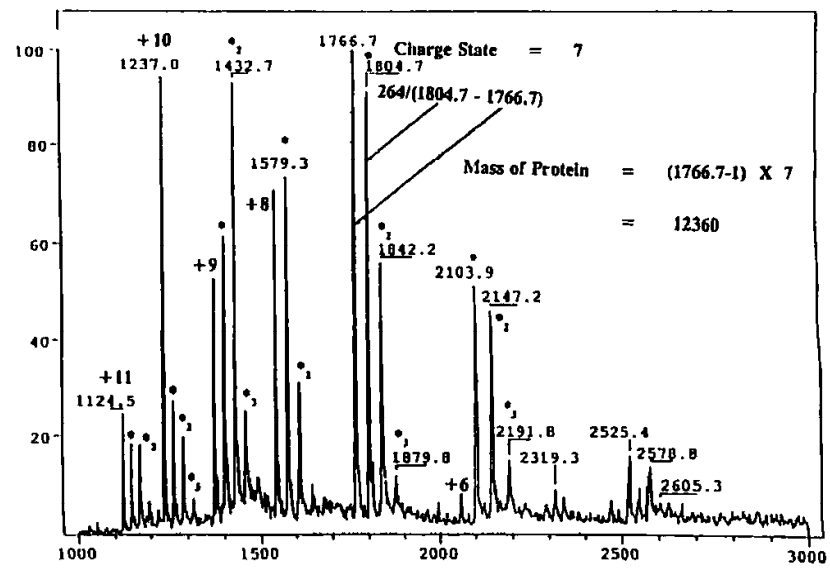

Figure 7. Mass spectrum of cytochrome $c$ in water with an 18-crown-6/MeOH sheatl. The asterisk $\left({ }^{*}\right)$ indicates the 18crown-6 adduct. Subscript to the asterisks denote the number of crown ether adducts. 
ability of charge sites for interaction. The apparent independence of the number of bound crown ethers at each charge state may have implications for the tertiary structure (gas phase or solution phase) of the protein and/or the mechanism of electrospray. These topics are beyond the scope of the current paper, but they are the subject of continuing research.

Mass of Apomyoglobin and Cytochrome $c$. From Figure 6 or 7, the charge state of any ion in the spectrum of myoglobin or cytochrome $c$ can be determined from the mass difference of any uncomplexed ion and its singly complexed adduct as follows:

$$
\text { charge state }=264 /\left(M_{(\text {complexed })}-M_{\text {(uncumplexed })}\right)
$$

Where $M_{\text {(cumplexed) }}$ is the mass-to-charge ratio value of a singly complexed protein ion, $M_{\text {cuncomplened }}$ is the mass-to-charge ratio value of the complementary uncomplexed ion, and charge state is an integer.

Assuming proton cationization, the mass of the protein then can be calculated accordingly:

$$
\text { mass of protein }=\left(M_{\text {(uncumpleved }}-1\right) \times \text { charge state }
$$

Sample calculations for the mass of myoglobin using eqs (2) and (3) are shown below and in Figure 6:

\section{Myoglobin:}

$$
\begin{aligned}
\text { charge state }_{(15+2.1)}= & 264 /(1566.4-1542.1)=(10.9) \\
= & 11 \quad \text { from eq } 2 \\
\text { mass of myoglobin }= & (1542.1-1) \times 11 \\
= & 16952 \mathrm{u}(\text { Actual mass } 16,950
\end{aligned}
$$

[Ref. 39]) from eq 3

Attempts to generate CNL scans from the loss of 18-crown-6 from highly charged ions $(>10)$ have been unsuccessful. It is still somewhat unclear why this is the case, but it is possible that it may be due to a combination of factors. Ions spend a relatively short period of time in the collision cell. Because of this and because there is an enhanced likelihood that a crown ether knocked off one charged site may be abstracted by a second cationic center (due to the large number of charges), it is conceivable that a crown ether cannot be completely freed from the highly charged protein ion during the collision time frame. [It also has been postulated that the problem here might be the low centerof-mass collision energy available for highly charged ions, because these tend to be heavy (editor's comments)]. Nevertheless, it would be interesting to perform the experiment with an ion trap or ion cyclotron resonance mass spectrometer whereby the time frame of collisions could be greatly enhanced. Without the ability to do CNL scanning of highly charged proteins, the practical utility of the crown adducts for the analysis of proteins is analogous to the utility of metal cation adducts with peptides.

Admittedly, the practical utility of crown ether adduction for proteins may be limited because the charge state and mass of the protein may be determined readily and accurately by commercially available biomass deconvolution programs that have a built-in multiplex advantage and appear to do an adequate job. It should be noted that the multiplex advantage also can be applied to the crown ether adduct spectra simply by determining the mass of the protein (by using eqgs 2 and 3 ) for every set of ions available in the spectrum. By utilization of crown ether adduction, however, the mass of a protein may be determined by only one protein ion and its adduct. This avails the possibility of accurate determination of protein mass with shorter scan ranges and concomitantly increases the number of scans per unit time. The problem of excessive scan times with respect to peak width in the analysis of proteins by chromatography is often a serious drawback of electrospray mass spectrometric detection. It must be pointed out that although the mass of a protein also may be determined by biomass deconvolution algorithms of only two protein ions, there is a built-in assumption that both ions originate from the same protein. Although this assumption readily can be made for analysis of known protein solutions, it is not made as easily during the analysis of complex protein mixtures with coeluting analytes. With the crown ether mass shift, the assumption that two ions originate from the same protein can be corroborated with the adduct mass shift. In this manner, the crown ether mass shift can determine the presence of coeluting analytes. Finally, the crown ether mass shift may be used in conjunction with the biomass deconvolution and provides twice as many peaks for a single protein. It should be noted, however, that the potential benefits of additional peaks may have to be balanced with the possibility of charge suppression and competition from the additional ions.

\section{Potential Uses and Implications of Crowen Ether Complexation to the Analysis of Peptides}

Perhaps the greatest potential advantage of utilization of crown ethers may be realized best in the analysis of complex mixtures of peptides, in particular trypsindigested proteins. Because trypsin cleaves at the C-side of lysine and arginine, peptide fragments with two amine groups are present on all peptide fragments. There exists therefore the potential that all trypsin fragments will yield doubly charged jons. This would make the mixture amenable to CNL (132 u) scanning (for 18-crown-6 adducts), which conceivably could yield a spectrum that consists of a single peak per peptide fragment (as observed in Figure 4). From the spectrum, the mass of each peptide fragment can be 
determined. Complementary data could be obtained by CNL (264 u) scanning. One drawback to this scenario versus a prior chromatographic separation is that isobaric peptide fragments could not be distinguished (although they may be with a high resolution mass analyzer). In many respects, the information content of such an experiment may be similar to that obtained by a matrix-assisted laser desorption time-of-flight experiment of the trypsin digest, but with enhanced resolution. The number of peptide fragments is generally similar to the number analyzed in solution 2 . Finally, if chromatographic or electrophoretic separation is required, employment of the crown ether within a methanol sheath, combined with CNL (132) scanning may simplify the mass chromatogram greatly and conceivably could reduce the scanned mass range by a factor of 2 .

\section{Elimination of Buffers and Sample Size Limitations}

Biological samples frequently are delivered to the mass spectrometrist in a matrix suitable for biological preservation but very detrimental to ESI analysis. For this reason, a prior sample cleanup and/or desalting often is required. Although this may reduce a number of compounds that may cause charge suppression, buffers and ion-pairing reagents, which are required for high-performance liquid chromatography (HPLC) or capillary zone electrophoresis (CZE), may add other potential charge suppressors. Because it is possible that the $\mathrm{CNL}$ experiment with crown ether can be performed by continuous infusion, contamination of the sample by ion-pairing reagents or buffers (used extensively in HPLC or CZE) can be avoided. It should be noted that an initial sample cleanup still must be performed prior to analysis by the continuous infusion method. With the elimination of buffers or ion-pairing agents such as trifluoroacetic acid, negative ion ESI (ESI - ) spectra are generated more easily. The ESI spectra of peptides, which also lack sodium adducts, may complement the ESI + data by using CNL scanning. A simple switchover to negative ion detection is possible even while the crown ether sheath is being infused. Crown adducts are not observed via ESI scanning apparently because the crown ether binds only to positive sites. Our current investigation concerns whether crown ether addition actually enhances ESI - data via a "crown ether effect" mechanism. That is, just as crown ethers can enhance the rate of nucleophilic attack in organic reactions by "tying up" positive counterions, it is possible that an increased negative ion current may be allowed due to an analogous "tying up" of positive ions within the charged droplet. Finally, because all the recommended experiments have been performed by using continuous infusion, sample volume will not be restricted by sample loop size or chromatographic concerns. It should be noted that the crown ether adduction method also may be performed when the sample is limited and when loop injection is desired.

\section{Conclusion}

Crown ether adduction can be exploited to determine an unambiguous mass-to-charge ratio and mass of single peptides. The method can be applied to the analysis of relatively complex mixtures of peptides and/or proteins. For peptides, the noncovalent crown ether complex may be detected by tandem mass spectrometry by using a constant neutral loss scan. This permits the facile determination of charge states of complex peptide solutions with greatly simplified spectra and the capability to distinguish isobaric ions with different charge states. The method may be used in conjuction with chromatography with the additional feature of separation based on charge state. In some cases the method may be used for the rapid analysis of a large number of peptides without chromatography and without sample volume limitations or limitations that result from ion-pairing reagents that frequently are employed with chromatographic techniques. For proteins, the charge state and mass of a protein may be determined from a single protein ion and its singly complexed satellite ion.

\section{References}

1. Braun, T.; Zsindely, S. Trends Anal. Chem. 1992, 11, 307.

2. Neubauer, G.; Anderegg, R. J. Anal. Chem. 1994, 66, 1056.

3. Senko, M. W.; Beu, S. C.; McLafferty, F. W. I. Am. Soc. Mass Spectrom. 1993, 4, 848.

4. Cunniff, J. B.; Vouros, P. Rapid Commun. Mass Spectrom. 1994, $S, 715$.

5. Ganem, B.; Li, Y.; Henion, J. D. J. Am. Chem. Soc. 1991, 113, 6294.

6. Katta, V.; Chait, B. T. I. Am. Chem. Soc. 1991, 113, 8534.

7. Ganem, B.; Li, Y.; Henion, J. D. I. Am. Chem. Soc. 1991, 113 , 7818.

8. Ganguly, A. K.; Pramanik, B. N.; Tsarbopoulos, A.; Covey, T. R.; Huang, E.; Fuhrman, S. A. I. Am. Clkm. Soc. 1992, 114, 6559.

9. Loo, R. R. O.; Goodlett, D. R.; Smith, R. D.; Loo, J. A. I. Am. Chem. Soc, 1993, 115, 4391.

10. Haskins, N. J.; Camilleri, P. Rnpid Commmm. Mnss Spectrom. $1993,7,603$.

11. Huang, E. C.; Pramanik, B. N.; Tsarbopoulos, A.; Reichert, P.; Ganguly, A. K.; Trotta, P. P.; Nagabhushan, T. L.; Covey, T. R. J. Am. Soc. Mass Spectrom. 1993, 4, 624.

12. Goodlett, D. R.; Camp, D. G., II; Hardin, C. C.; Corregan, M.; Smith, R. D. Biol. Mass Spectrom. 1993, 22, 181.

13. Light-Wahl, K. J.; Springer, D. L.; Winger, B. E.; Edmonds, C. G.; Camp, D. G., II; Thrall, B. D.; Smith, R. D. I. Am. Chem. Soc. 1993, 115, 803.

14. Jaquinod, M.; Leize, E.; Potier, N.; Albrecht, A.; Shanzer, A.; Dorsselaer, A. V. Tetraltedron Lett. 1993, 34, 2771.

15. Allen, M. H.; Hutchens, W. T. Rapit Commun. Mass Spectrom. 1993, 6, 308.

16. Knight, W. B.; Swiderek, K. M.; Sakuma, T.; Calaycay, J.; Shevely, 1. E.; Lee, T. D.; Covey, T. R.; Shushan, B.; Green, B. G.; Shah, C. S.; Mumford, R.; Dickinson, T. A.; Griffin, P. R. Biodemistry 1993, 32, 2031. 
17. Smith, R. D.; Light-Wahl, K. J.; Winger, B. E.; Loo, J. A. Org. Mass Spectrom. 1992, 27, 811.

18. Smith, R. D.; Light-Wahl, K. J. Biol. Mass Spectrom. 1993, 22, 493.

19. Haskins, N. J.; Ashcroft, A. E.; Phillips, A.; Harrison, M. Rapid Commun. Mass Spectrom. 1994, 8, 120.

20. Sakairi, M.; Yergey, A. L.; Siu, K. W. M.; Le Blanc, J. C. Guevremont, R.; Berman, S. S. Anal. Chem. 1991, 63, 1488.

21. Winger, B. E.; Light-Wahl, K. J.; Smith, R. D. J. Am. Soc. Mass Spectrom. 1992, 3, 624.

22. Kebarle, P.; Tang, L. Anal. Chem. 1993, 65, 972A.

23. Johnstone, R. A. W.; Rose, M. E. I. Chem. Soc., Chem. Commum. $1983,65,1268$

24. Takahashi, T.; Uchiyama, A.; Yamada, K.; Lynn, B. C.; Gokel, G. W. Tetrahedron Lett. 1992, 33, 3825.

25. Bonas, G.; Bosso, C. Vignon, M. R. Rapid Commum. Mass Spectrom. 1988, 2, 88.

26. Sawada, M.; Okumura, Y.; Shizuma, M.; Takai, Y.; Hidaka, Y.; Yamada, H.; Tanaka, T.; Kaneda, T.; Hirose, K.; Misumi, S.; Takahashi, S. J. Am. Chem. Soc. 1993, 115, 7381.

27. Michaud, D. P.; Kyranos, J. N.; Brennan, T. F.; Vouros, P. Anal. Chem. 1990, 62, 1069.

28. Malhotra, N.; Roepstorff, P.; Hansen, T. K.; Becher, J. I. Am. Chem. Soc. 1990, 112, 3709.
29. Maleknia, S.; Brodbelt, J. I. Am. Chem. Soc. 1992, 114, 4295.

30. Zhang, H.; Dearden, D. V. I. Am. Chem. Soc. 1992, 114, 2754.

31. Katrizky, A. R.; Malhotra, N.; Ramanathan, R.; Kemerait, R. C.; Zimmerman, J. A.; Eyler, J. R. Rapid Commun. Mass Spectrom. 1992, 6, 25.

32. Zhang, H.; Chu, l.; Leming, S.; Dearden, D. V. I. Am. Chem. Soc. 1991, 113, 7415 .

33. Hiraoka, M., Ed. Croum Ethers and Analogous Compounds; Elsevier: Amsterdam, 1992.

34. Weber, E.; Toner, J. L.; Goldberg, l.; Vogtle, F.; Laidler, D. A.; Stoddart, J. F.; Bartsch, R. A.; Liotta, C. L. Crozin Ethers and Analogs; Wiley: London, 1989.

35. Inoue, Y.; Gokel, C. W., Eds. Cation Binding by Macrocycles, Complexation of Cationic Species by Crown Ethers; Marcel Dekker: New York, 1990.

36. Gokel, G. Crown Ethers and Cryptands; Black Bear Press Ltd.: Cambridge, England, 1991.

37. Cooper, S. R., Ed. Croum Compounds; Tounard Future Applications; VCH Publishers Inc.: New York, 1992.

38. Smith, R. D.; Loo, J. A.; Edmonds, C. G.; Barinaga, C. J.; Udseth, H. R. Anal. Chem. 1990, 62, 882. 